\title{
Research Paper \\ The Effectiveness of Acceptance and Commitment Therapy on Resilience, Meaning in Life, and Family Function in Family Caregivers of Patients With Schizophrenia
}

\author{
Somayeh Moghbel Esfahani ${ }^{1}$ (1), *Sayed Abbas Haghayegh ${ }^{1}$ (1)
}

1. Department of Psychology, Faculty of Humanities, Najafabad Branch, Islamic Azad University, Najafabad ,Iran.

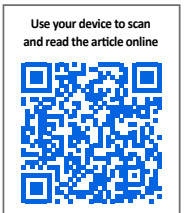

ditat Moghbel Esfahani S, Haghayegh S. [Effectiveness of Acceptance and Commitment therapy on Resiliency, Meaning of Life and Family Functioning in Caregivers of Patients With Schizophrenia (Persian)]. Quarterly of "The Horizon of Medical Sciences". 2019; 25(4):298-311. https://doi.org/10.32598/hms.25.4.298

https://doi.org/10.32598/hms.25.4.298

Key words:

Acceptance and commitment therapy, Resilience, Meaning in life, Family functioning, Schizophrenia

\section{AB STRACT}

Aims The caring of schizophrenia patients is a tiresome task for their families. This research aimed to examine the effectiveness of Acceptance and Commitment Therapy (ACT) on resilience, meaning in life, and family functioning in the caregivers of patients with schizophrenia.

Methods \& Materials This was a quasi-experimental study with a pretest-posttest and follow-up design and a control group. The study sample included 30 members of schizophrenia patients' families, referring to 2 neurological and psychological rehabilitation centers in Isfahan Province, Iran. By the convenience sampling method, the experimental group received 8 ACT sessions weekly; however, the control group received no treatment. Both groups were assessed in three phases; pretest, posttest, and one-month follow-up. The assessment tools consisted of Connor-Davidson Resilience Scale, Stagger Meaning in Life Questionnaire, and McMaster Family Functioning Scale. The obtained data were analyzed in SPSS by repeated-measures Analysis of Variance (ANOVA).

Findings The collected results indicated the significant difference of posttest and follow-up phases in terms of meaning in life and family functioning scores between the control and experimental groups $(P<0.05)$. Furthermore, there was a significant difference in posttest resilience scores $(P<0.05)$; however, there was no significant difference in the follow-up phase in this respect.

Conclusion The collected results suggested that ACT was effective on the meaning of life, family functioning, and resiliency; thus, it could improve such variables in the caregivers of patients with schizophrenia.

\section{Extended Abstract}

\section{Introduction}

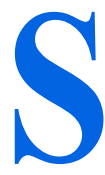

chizophrenia is a clinical syndrome that includes variable but profoundly destructive psychopathology that encompasses cognition, emotion, perception and other aspects of behavior. The occurrence of these manifestations varies by in- dividuals and over time, but the impact of the disease is always severe and usually lasting. Schizophrenia usually begins before the age of 25 , and none of the social classes are immune to it [1]. When the disease enters the family, like an uninvited guest, it disrupts the homeostasis of the family system in the domain of boundaries, roles, expectations, aspirations and hopes [2]. The first reported attention to the psychological problems of family caregivers of schizophrenic patients goes back to 1960 [3].

\section{* Corresponding Author:}

Sayed Abbas Haghayegh, PhD.

Address: Department of Psychology, Faculty of Humanities, Najafabad Branch, Islamic Azad University, Najafabad, Iran.

Tel: +98 (31) 42293030

E-mail: abbas_haghayegh@yahoo.com 
Resilience is defined as one's confidence in his/her ability to overcome stress or one's ability to maintain bio-psychological balance in adverse conditions [10]. The concept of resilience has been derived from observations in which many children have demonstrated the ability to achieve a new positive status despite adverse experiences [11]. Resilience is important as a significant indicator to counter the negative consequences of chronic diseases such as cancer [12, 13].

Family functioning is a joint effort to establish and maintain balance in the family. One of the positive functions of a family is to support its members in stressful and unpleasant situations. The role of family is to adapt itself to life changes, resolve conflicts, unite family members to succeed in achieving discipline patterns, respect the boundaries between individuals, enforce the principles and laws governing the family institution in order to protect the entire family system [18].

Acceptance and commitment therapy approaches emphasize acceptance of negative thoughts and feelings, not change of thoughts and feelings; thus, by reducing one's focus on negative thoughts, this approach may be beneficial to families of schizophrenic patients and improve their mental health and psychological well-being. Acceptance and commitment therapy has six central processes that lead to psychological flexibility: acceptance, blame, self as context, connection with the present, values and committed action. Acceptance and commitment therapy has a significant increase in the tendency to engage in challenging activities while also experiencing difficult emotions.

\section{Methods}

Design of the present research was quasi-experimental with pre-test, post-test and follow-up (one month) with control group. The statistical population of the study was the family of all schizophrenic patients in Isfahan province in 2015 . Subjects were selected through convenience sampling from among the clients' families in two daily neurological and psychiatric rehabilitation centers Baran and Raha in Isfahan province. Then, all of their primary caregivers were invited over the phone, and after giving explanations about the study method, they were asked for a written consent to participate in the study. 30 volunteers (out of 81 schizophrenic patients who had psychiatric records in these centers) were selected for the experimental and control groups.

\section{Results}

The demographic characteristics of the research sample and descriptive findings are presented in Table 2 and Table 3 respectively.

\section{Discussion}

In the present study, the efficacy of acceptance and commitment based treatment on resiliency, meaning in life and family functioning of family caregivers of schizophrenic patients was investigated. The results are evaluated below.

The results regarding the effectiveness of intervention on the level of resilience showed that there was a significant difference between the pre-test and post-test in the experimental group, but the difference between the post-test and the follow-up was not significant and compared to the follow-up, the post-test scores of the participants did not increase. The results of this study are somewhat consistent with those of Eilenberg et al [26].

\section{Conclusion}

The outcomes of this study show that this treatment can be a good option for improving the inter-family interactions of these patients and enduring the unintended psychological consequences of this disorder among their family members. However, it seems that more therapeutic sessions are needed to increase the resiliency of the caregivers of these patients.

One of the major limitations of this study is that convenience and non-double-blind sampling of this study may be hampered to some extent by the generalizability of the results and external validity of the study. Other limitations of this study include the lack of control over some variables such as the proportion of caregivers, the duration of illness, and the psychological status of caregivers themselves, which may have influenced the results.

\section{Ethical Considerations}

\section{Compliance with ethical guidelines}

This study has obtained its ethical approval from the Research Ethics Committee of Islamic Azad University of Najafabad branch (Code: IR.IAU.NAJAFABAD.REC. 1397.032). Informed consent was obtained from the participants and they were assured of the confidentiality of their information. After the end of study, the control group also received four educational sessions on Schizophrenia and how to communicate with these patients within the family.

\section{Funding}

This research did not receive any specific grant from funding agencies in the public, commercial, or not-forprofit sectors. 


\section{Authors' contributions}

Conceptualization, methodology, investigation, and data collection: Somayeh Moghbel Esfahani; Data analysis and writing: Sayed Abbas Haghayegh.

Conflicts of interest

The authors declared no conflict of interest. 


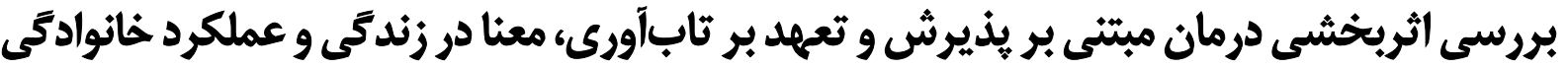

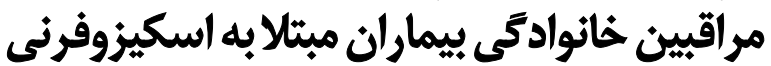

\author{
سميه مقبل اصفهانى' هـ، "سيد عباس حقايق' \\ 1. كروه روان شئاسى، دانشكده علوم انسانى، واحد نجف آباد، دانشكاه آزاد اسلامى، نجف آباد، ايران.
}

\begin{abstract}
حكSد

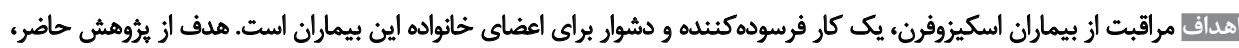

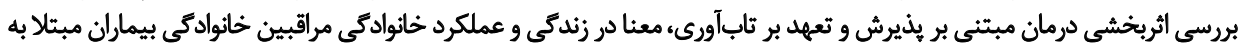
اسكيزوفرنى بودها استيت.

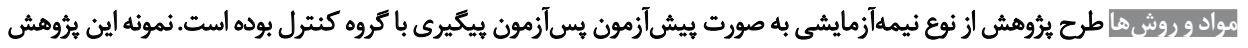

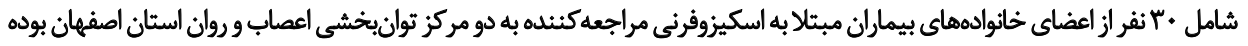

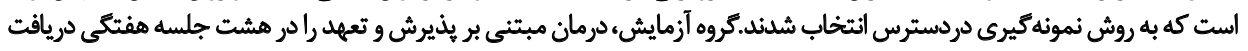

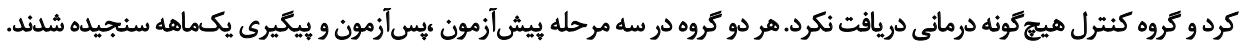

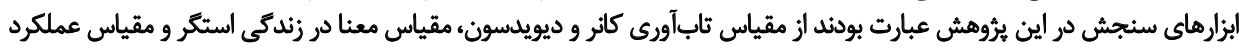

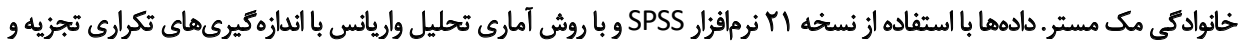
تحليل شُنديند.

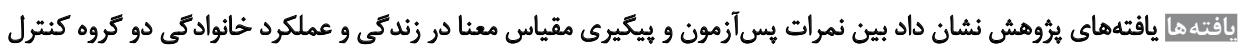

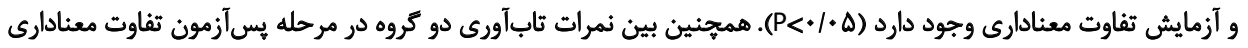

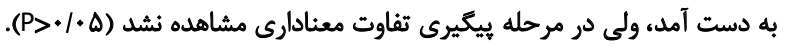

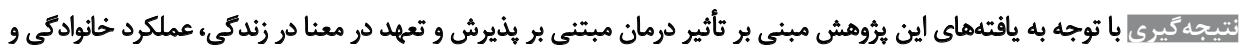

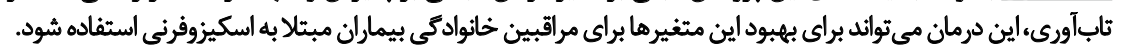

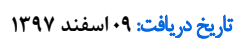

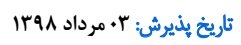

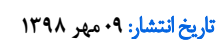

كليدوارهها: درمان مبتني بر يذيرش

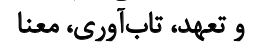

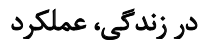

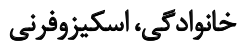

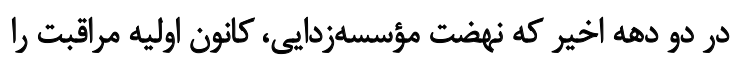

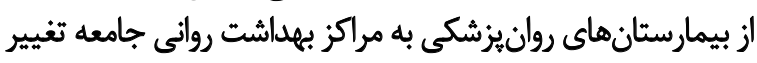

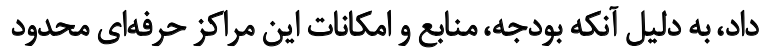

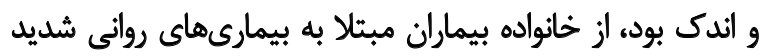

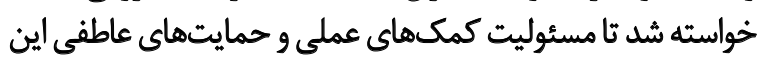

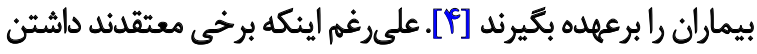

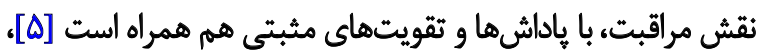

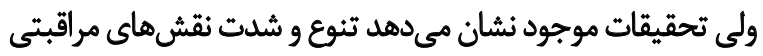

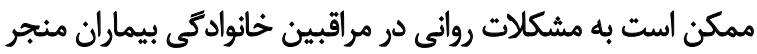

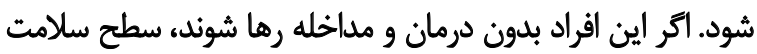

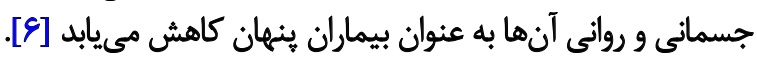

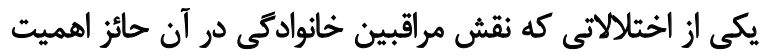

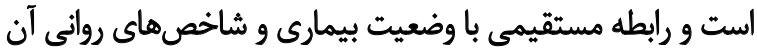

$$
\text { دارد اسكيزوفرنى است من [V] }
$$

مقلمه

اسكيزوفرنى '،سندرمي بالينى شامل آسيبشناسى روانى متغير،اما

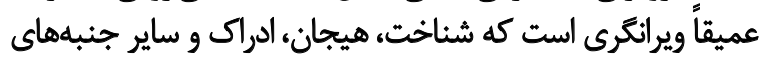

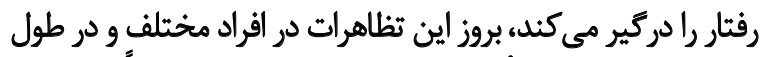

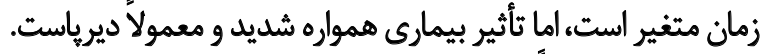

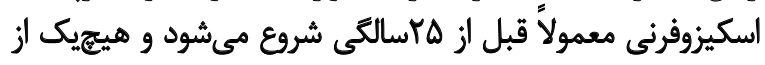

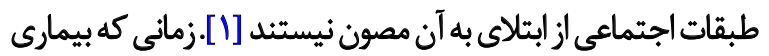

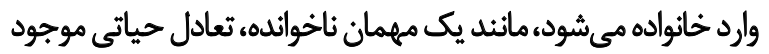

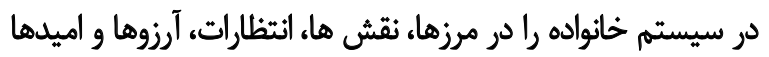

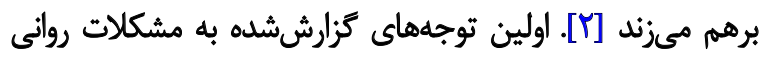

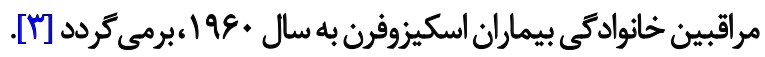

-

\section{Schizophrenia}

* نويسئده مسئول:

دكتر سيد عباس حقايق

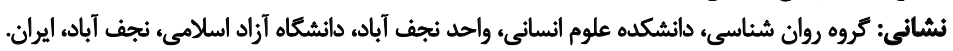

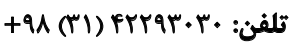
يست الكترونيكى: abbas_haghayegh@yahoo.com 


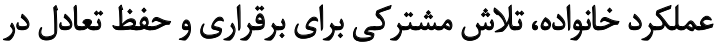

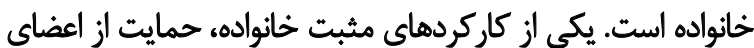

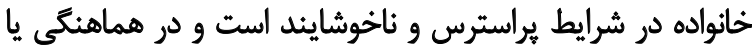
تطابق با تغييرات ايجادشده در طول حيات، حل تضادها و تعارض وضانها،

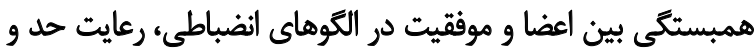

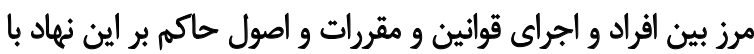

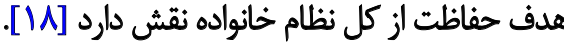

عملكرد خانواده با سلامت روانى اعضا ارتباط دارد و در خانوادههاييى

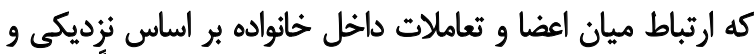

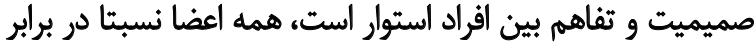

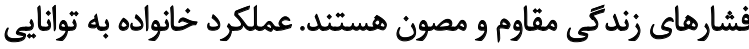

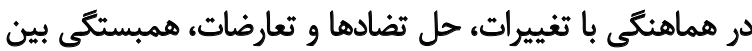

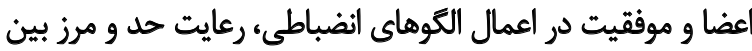

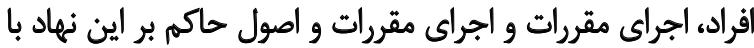

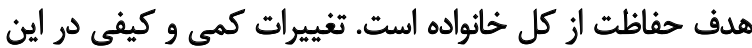

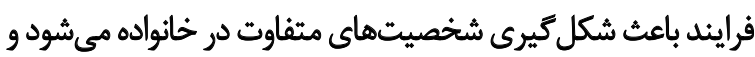

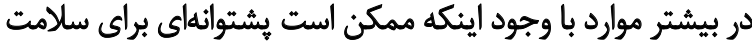

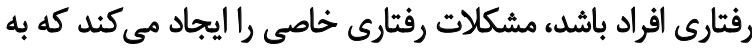

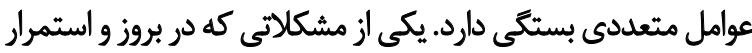

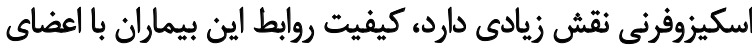

خانوادهان است [19].

برخى مداخلات درمانى نظير آموزش، حمايت و رواندرمانى

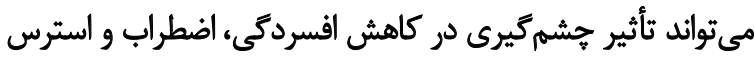

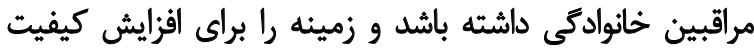

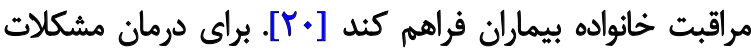

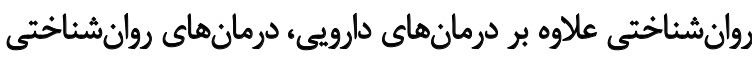

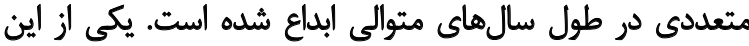

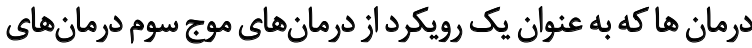

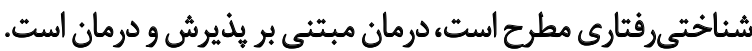

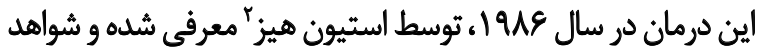

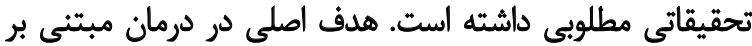

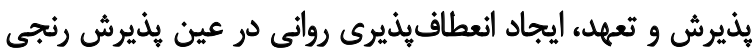

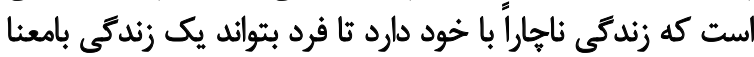

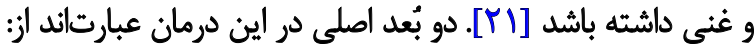

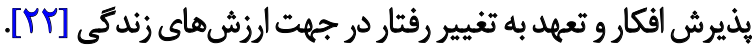

رويكردهاى درمان مبتنى بر يذيرش و تعهد بر بذيرش افكار و و

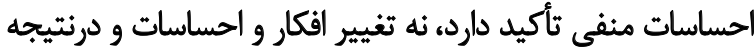

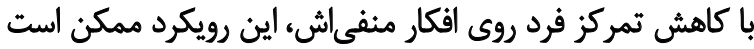

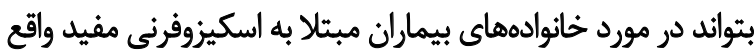

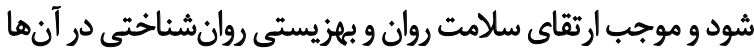

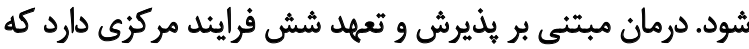

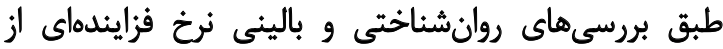

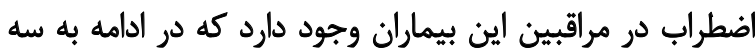

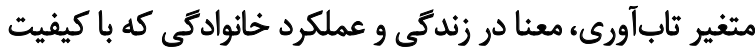
مراقبت مراقبين خانوادگى اينى اين بيماران رابط رابطه مستقيمى داردي،

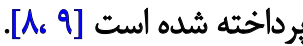

تاب آورى به عنوان اطمينان فرد به توانايىهايش براي غلبه بر بر برائ

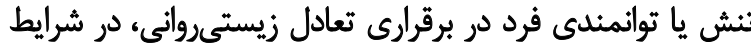

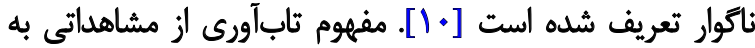

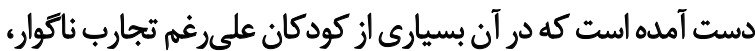

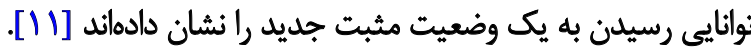

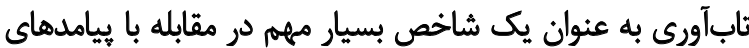

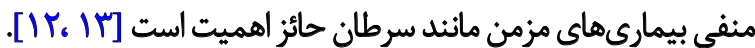
با توجه به تحقيقات صورتكرفته تابآورى يكى از مفاهيم و

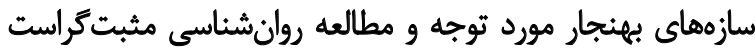

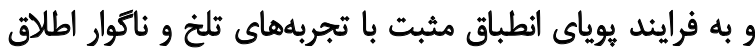

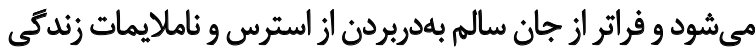

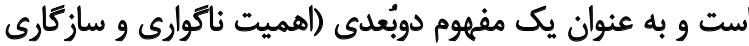

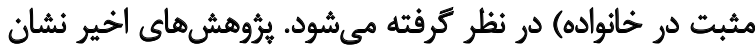

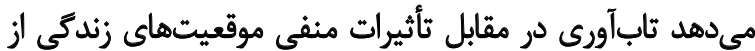

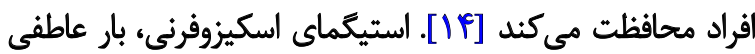

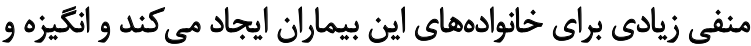

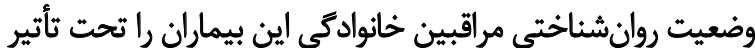

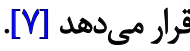

معنا در زندكى، يك سازه شخصى است كه با بهزيستى رئى

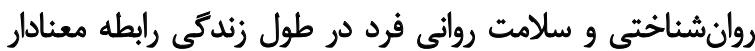

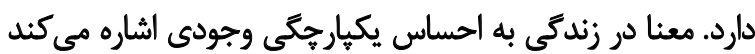

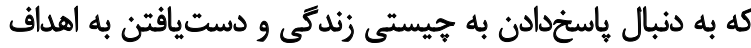

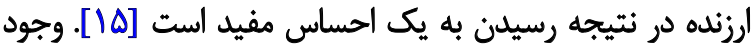

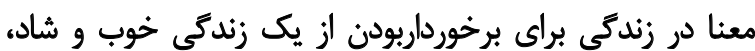

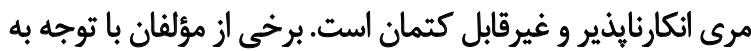

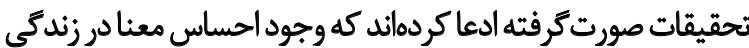

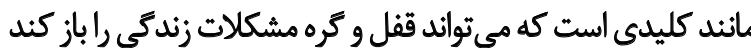

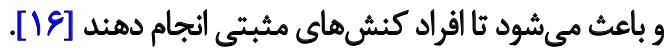
مشكل در معناي زندكى يكى از عوامل مهرم در احساس نالميدى

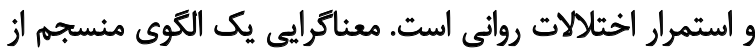

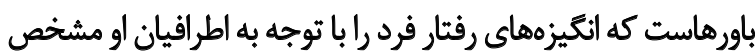

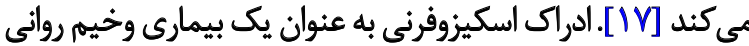

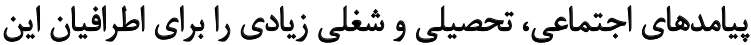

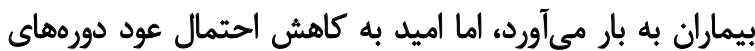

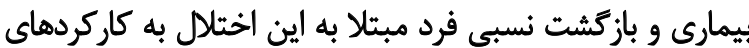

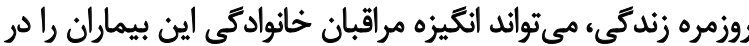

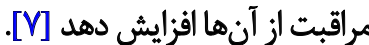




\section{مواد و روشها}

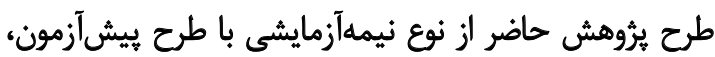

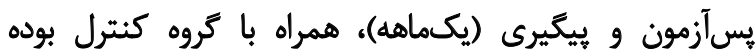

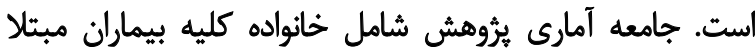

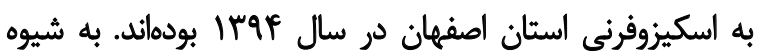

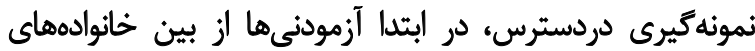

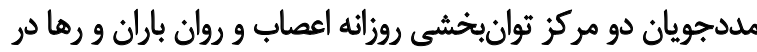

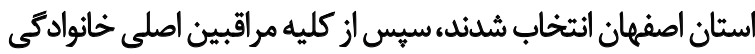

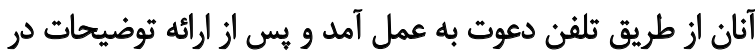

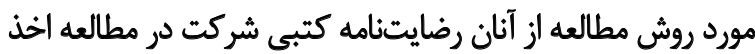

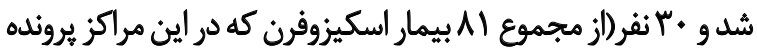

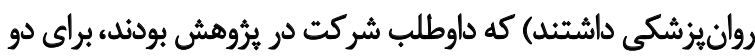

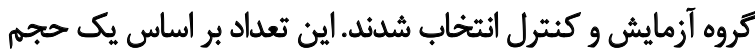

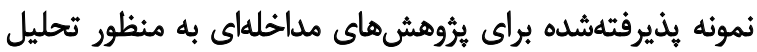

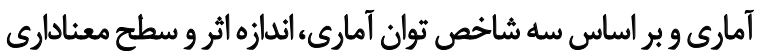

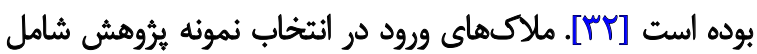

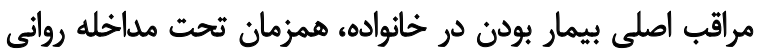

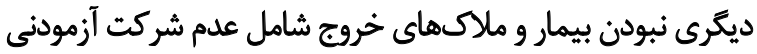

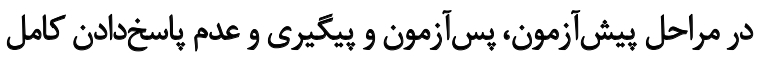

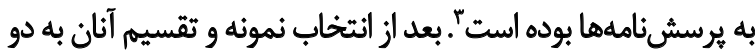

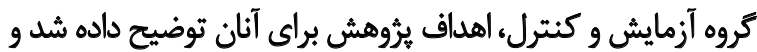
كروه كنترل در ليست انتظار باقى ماند.

شيوه اجرا

بعد از انتخاب •ب نفر در دو كروه آزمايش و كنترل، جلسه اول

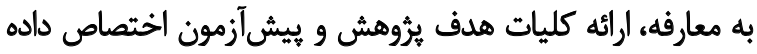

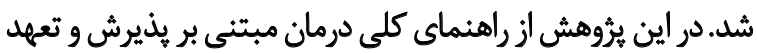

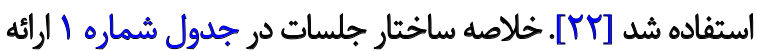

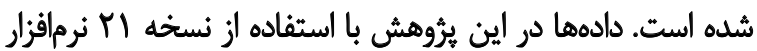

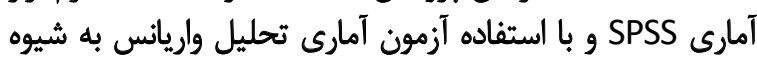
اندازهيرى هاى تكرارى، تجزيه و تحليل شد.

برسش بامه ثابآورى

اين مقياس در سال ץ +. ؟، توسط كانر و ديويدسون ساخته شده

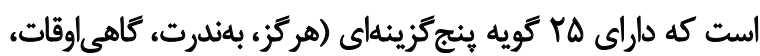

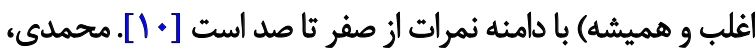

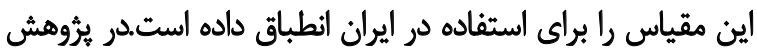

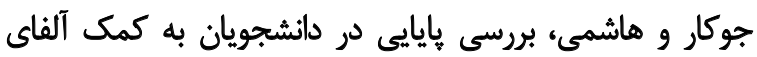

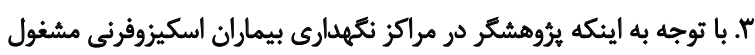

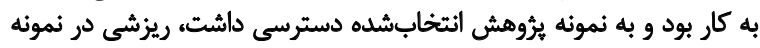

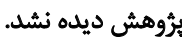

به انعطافيذيرى روانشناختى منجر ميشود اين شش فرايند

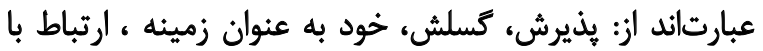

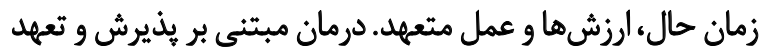

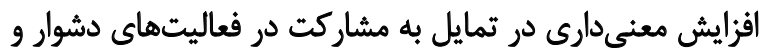
در عين حال تجربه هيجانات دشوار دار را نشان داده است.

فرايندهاي مركزى درمان مبتنى بر بذيرش و تعهيد به افراد

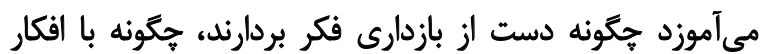

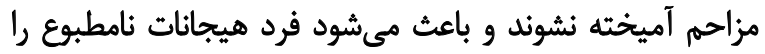

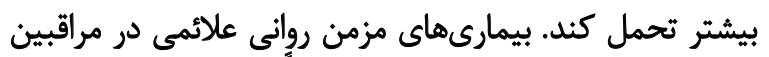

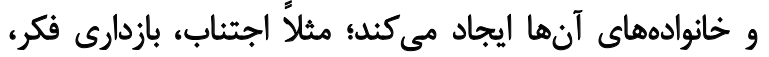

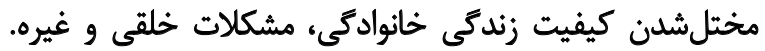

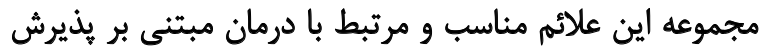

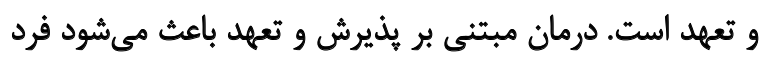

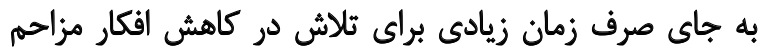

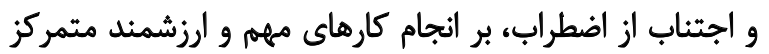

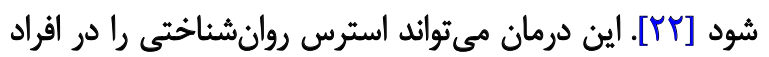

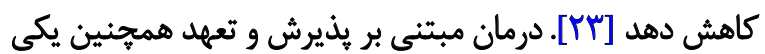

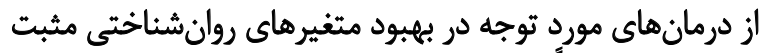

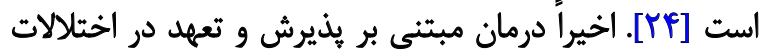

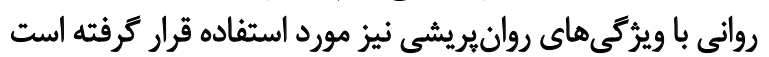

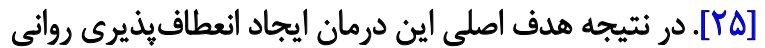

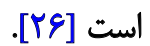

در يُروهش هاى خارجى، مك هاكى، در رابطه با اثربخشى درمان

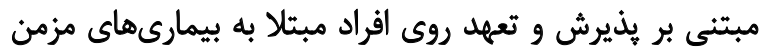

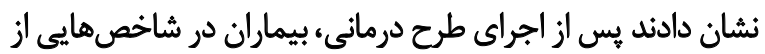

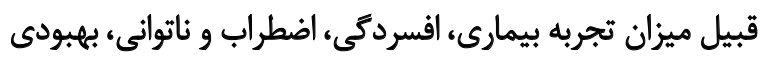

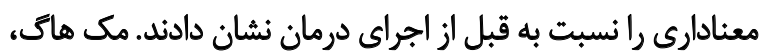

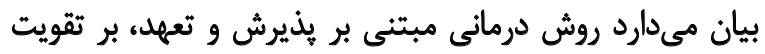

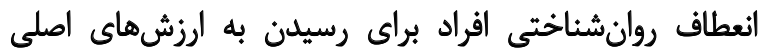

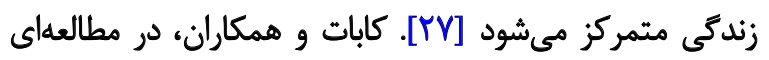

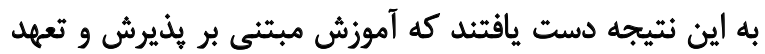

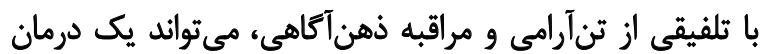

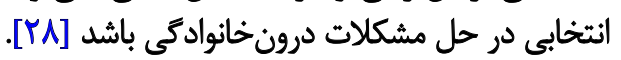

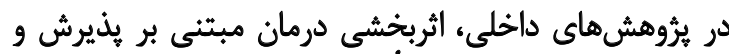

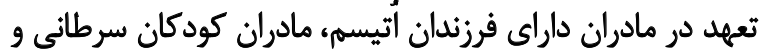

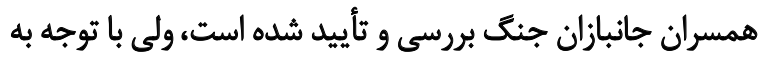

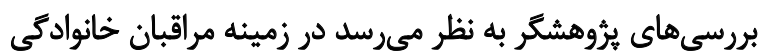

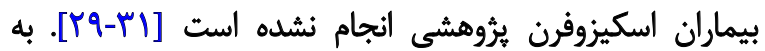

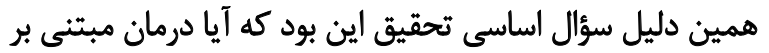

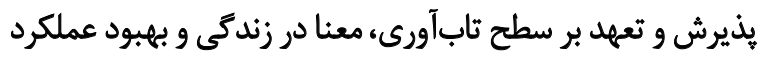

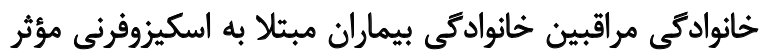

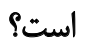


جدول ا. خلاصه محتواى جلسات درمانى

\begin{tabular}{|c|c|c|}
\hline تكثيك & هدف & 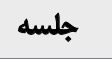 \\
\hline راهبردهاي كتترل به عنوان مسثله با كمك استعاره شُص در جاه & أشناييى و أموزش در خصوص درمان هبنتى بر هذيرش و تعهد & 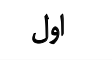 \\
\hline كثترل دئياى بيرون در مقابل دنياى درون با كمى استعاره دونات رزلهاى & درهاندكى خلاق و بررسى راهبردهاي كتثرل خاصى كه تاكنون فرد & دو \\
\hline بررسى تمايل به جاى اجتناب با كمى استعاره كدا & 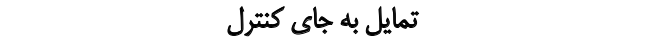 & سوم \\
\hline آموزش كسلش در مقابل آميختكى شناختى با كمك استعاره قطار & آموزش كسلش در مقابل آميختكى شناختى با كمك استعاره قطار & جهارج \\
\hline 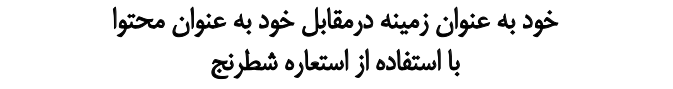 & حركت به سمت يك زندكى ارزشهند با يك خود يذيراو مشاهدهر & يَجْمَ \\
\hline تصريح ارزش ها با استفاده از استعاره تشييع جنازه & ايجاد الكوهاى منعطف رفتار از طريق مواجهه ارزش محور & شششم \\
\hline زندكّى در زمان حال از طريق ذهن أكاهى & توسعه خزانه رفتارى و الكوهاى منعطفتر ياسخدهى به افكار مزاحم و & هفتم و هشتم \\
\hline
\end{tabular}

أنتوانث

با هدف توصيف ويثزى هاى سازمانى و ساختارى خانواده تهيه شده

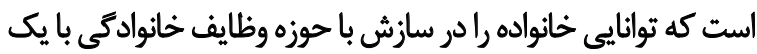

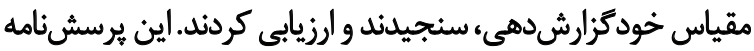

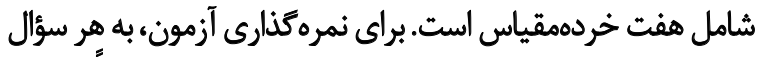

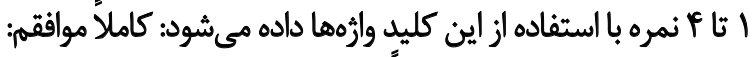

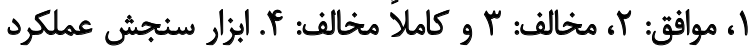

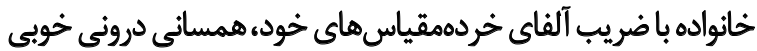

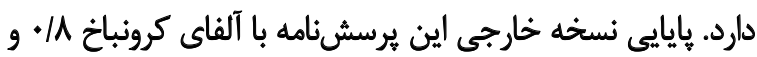

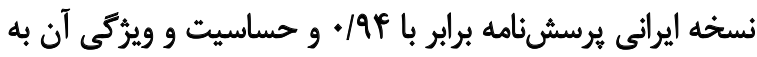

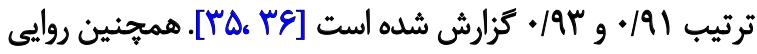

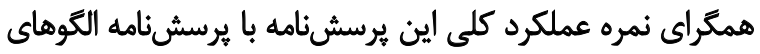

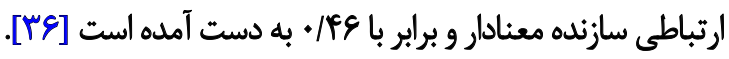

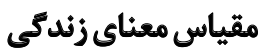

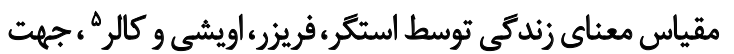

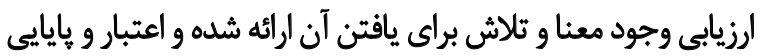

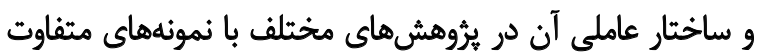

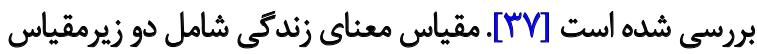

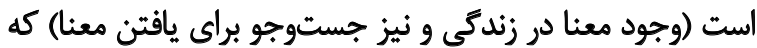

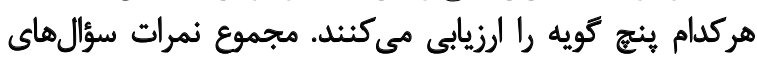

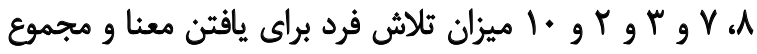

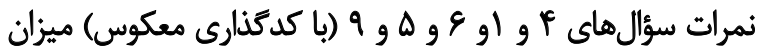

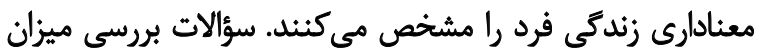

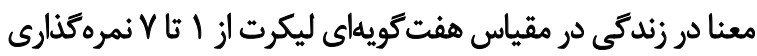

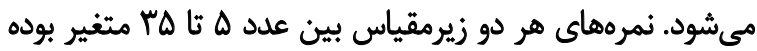

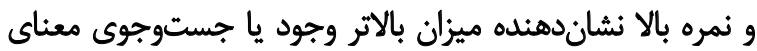

كرونباخ، برابر با AY/ به دست آمده [Tس]. همجنين نتايج آزمون

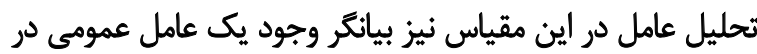

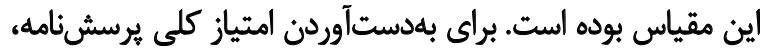

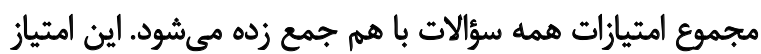

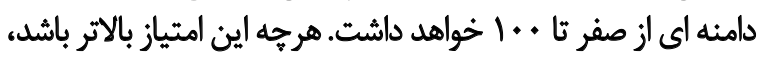

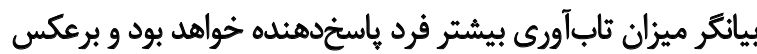

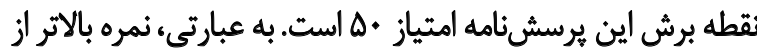

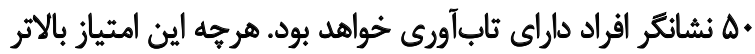

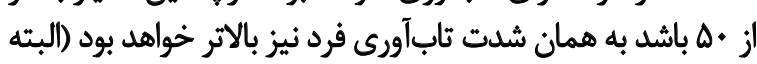

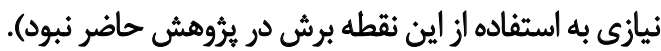

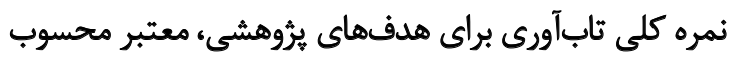

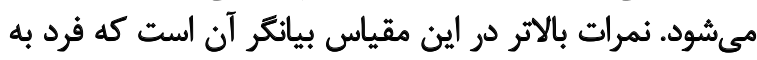

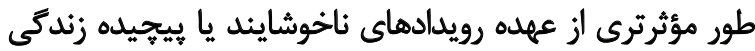

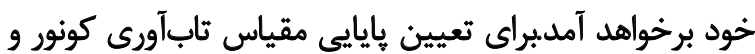

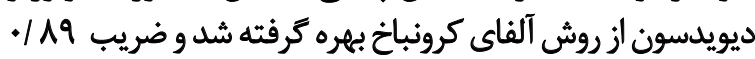

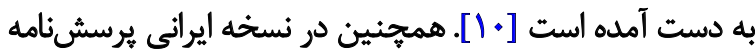

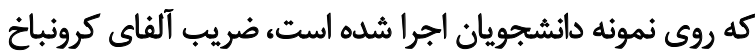

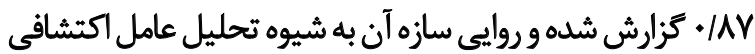

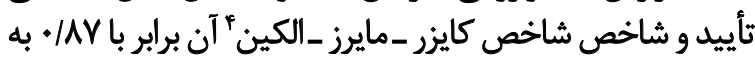

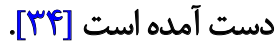

\section{يرسش نامه عملكردخانوادكي}

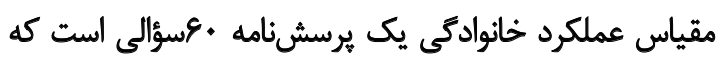

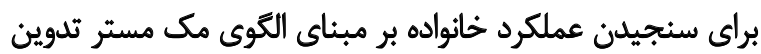

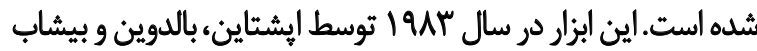




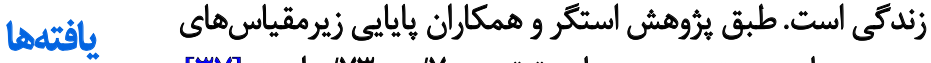

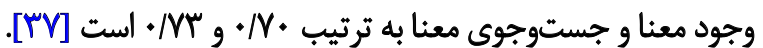

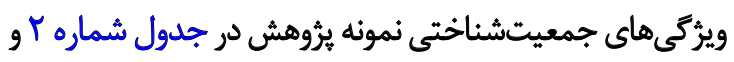

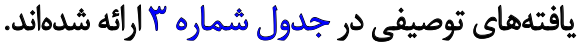

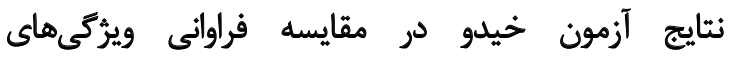

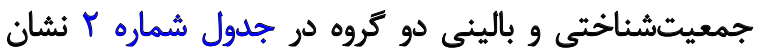

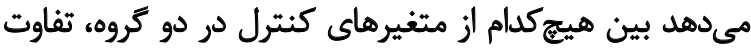

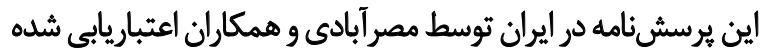

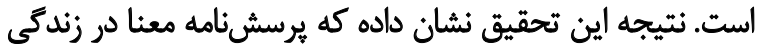

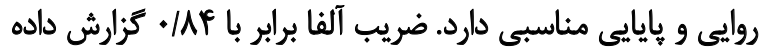

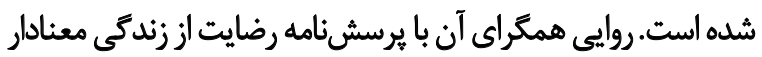

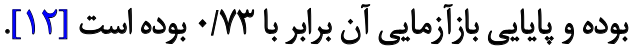

جدول r. دادهاي توصيفى مربوط به متغيرهاي جمعيت شناختي و بالينى

\begin{tabular}{|c|c|c|c|c|}
\hline \multirow{2}{*}{ سطح معنى دارى } & \multirow{2}{*}{ جي } & \multicolumn{2}{|c|}{ فراوانى (دوصد) } & \multirow[t]{2}{*}{ شاخصهاى آمارى . } \\
\hline & & كتترل & أزمايش & \\
\hline \multirow{3}{*}{$\cdot / m \cdot 1$} & \multirow{3}{*}{ rpe.. } & $V(F \& / V)$ & $\Delta(r / T)$ & زن \\
\hline & & $\Lambda(\Delta M / M)$ & 1. $(E \& / N)$ & مرد \\
\hline & & $10(1 .)$. & $10(1 . .0)$ & مجموع \\
\hline \multirow{4}{*}{.$/ r n^{\prime}$} & \multirow{4}{*}{ M... } & $A(\Delta r / M)$ & $\varepsilon(f \cdot)$ & 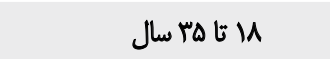 \\
\hline & & $r(1 r / r)$ & $q(f \cdot)$ & 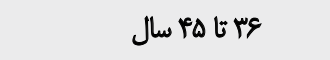 \\
\hline & & $\Delta(\pi / M)$ & $r(r \cdot)$ & بيشتر از لهال سال \\
\hline & & $10(1++)$ & $10(1 \cdot+)$ & مجموع \\
\hline \multirow{3}{*}{ - PEEA } & \multirow{3}{*}{$.10 M$} & $1 \cdot(88 / V)$ & $V(f \& / V)$ & مجرد \\
\hline & & $\Delta(M / M)$ & $\Lambda(\Delta r / T)$ & مثتاهل \\
\hline & & $10(1.0)$ & $10(1 . .0)$ & مجموع \\
\hline \multirow{4}{*}{$.1 \cdot \Delta r$} & \multirow{4}{*}{$r / A+}$. & $f(T \& M)$ & $I(E / N)$ & هذت بيمارى: ا ثا ه سال \\
\hline & & $r(1 r / r)$ & $q\left(f^{\circ}\right)$ & 8: • ا سال \\
\hline & & $9(9 \cdot)$ & $\Lambda(\Delta r / T)$ & بيشتر از •ا سال \\
\hline & & $10(1+)$. & $10(1 . .+)$ & مجموع \\
\hline \multirow{3}{*}{.$/ T r^{\infty}$} & \multirow{3}{*}{$\mathbb{M r} \cdot$} & $q(\varphi \cdot)$ & $q(\varepsilon \cdot)$ & سابقه بيمارى جسمى: خير \\
\hline & & $\varepsilon\left(r^{*}\right)$ & $\varepsilon(f \cdot)$ & 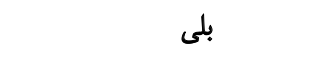 \\
\hline & & $10(1+\infty)$ & $10(1++)$ & مجموع \\
\hline \multirow{3}{*}{$\cdot 1 \cdot \mathrm{V}$} & \multirow{3}{*}{ F/AMT } & $\|(M / T)$ & $11(N / \pi)$ & سابقه خودكثى: خير \\
\hline & & $F(T \& / V)$ & $F(r \& / V)$ & 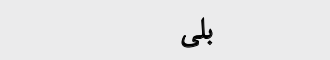 \\
\hline & & $10(1 \cdots)$ & $10(1 \cdot)$. & مجموع \\
\hline \multirow{3}{*}{ 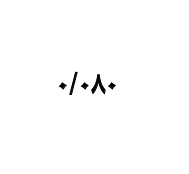 } & \multirow{3}{*}{ elims } & $\mathbb{I r}(\Lambda \& N)$ & $\mathbb{I r}(\Lambda \in \mathbb{N})$ & سابقه زندلن بازداشت: حير \\
\hline & & $r(M r / T)$ & $r(I m / r)$ & 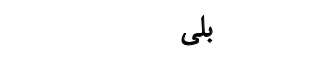 \\
\hline & & $10(1 \cdots)$ & $10(1.0)$ & مجموع \\
\hline \multirow{3}{*}{. MIA } & \multirow{3}{*}{.$/ 1 m r$} & $11(N / T)$ & $1 \cdot(8 / V)$ & سابقه بسترى: خير \\
\hline & & F(TEM) & $\Delta(\pi / T)$ & 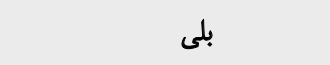 \\
\hline & & $10(1+\cdots)$ & $10(1.0)$ & مجموع \\
\hline
\end{tabular}

intion 
جدول r. ميانكين و انحراف معيار نمرات معناى زندكى، عملكرد خانوادكى و تابآورى

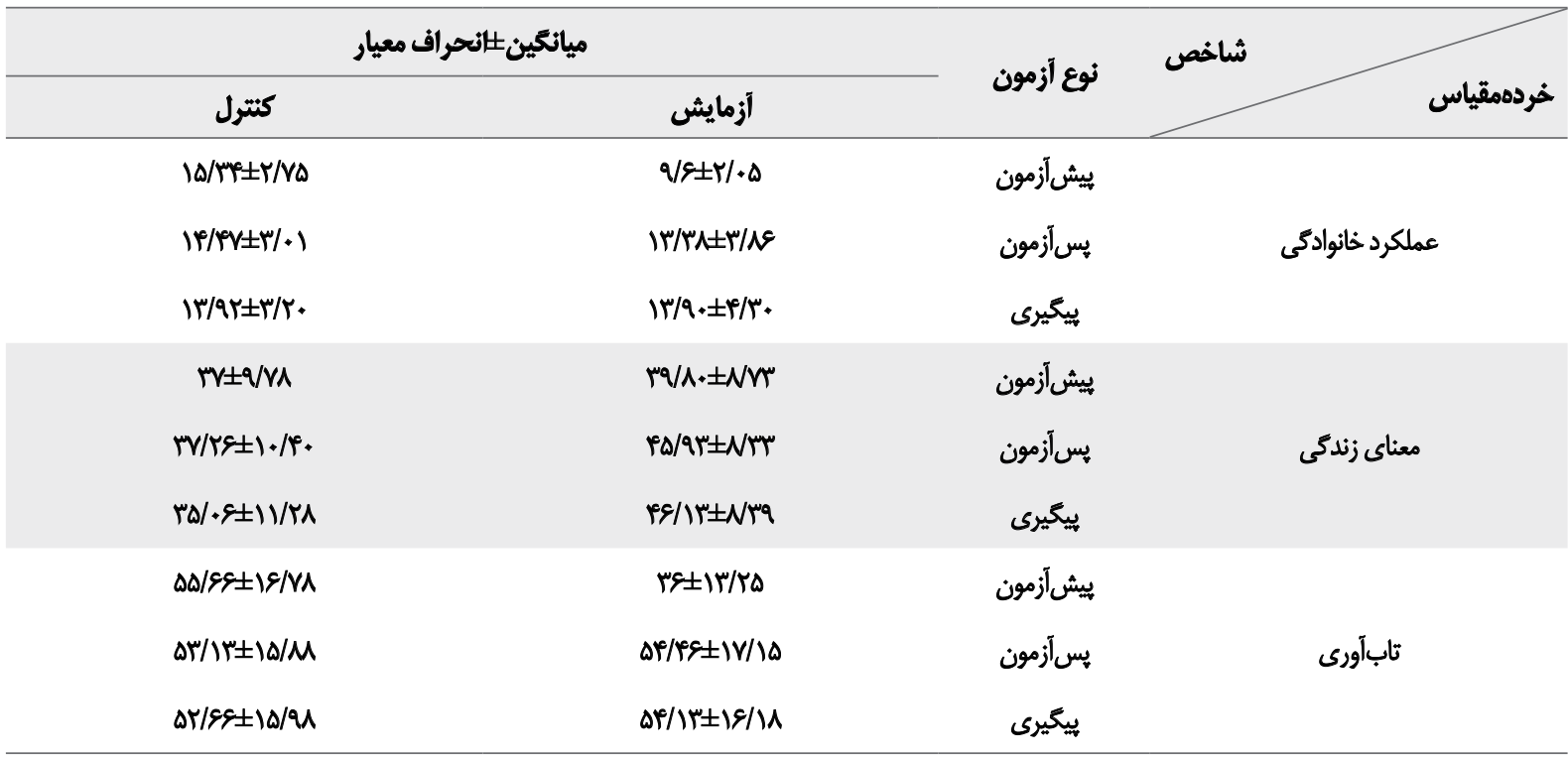

أنّوانث

تكرارى در مراحل بيش آزمون، يسآزمون و ونيكيرى امكانيذير است.

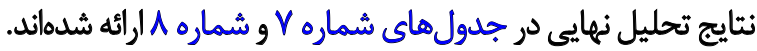

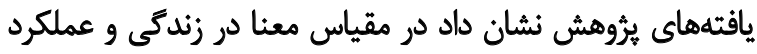

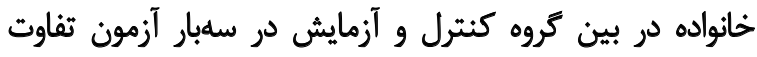

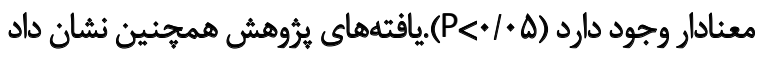

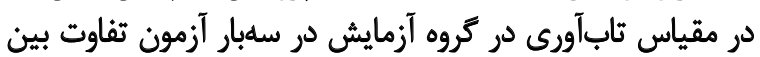

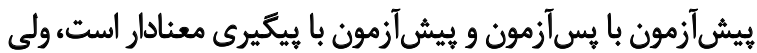

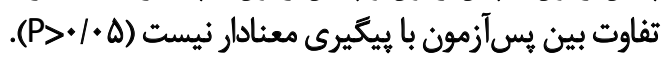

بحث

در يرؤهش حاضر اثربخشى درمان مبتنى بر يذيرش و و تعهد بر سطح

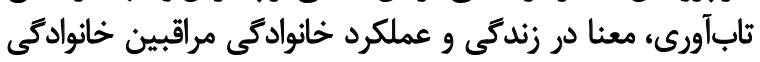

معنى دار نيست و نياز به كنترل آنها نيست. نتايج جدول شمان شماره

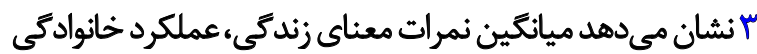

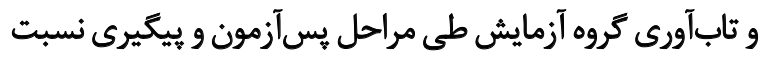

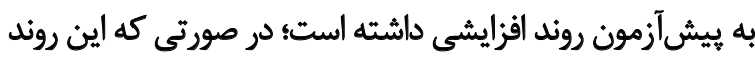
در تروه كنترل كاهشى بوده است.

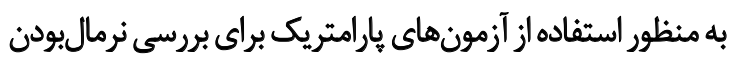

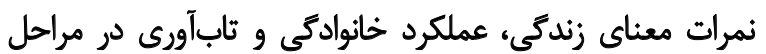

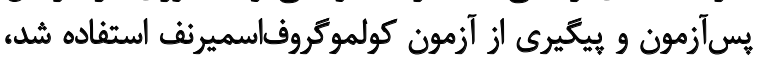

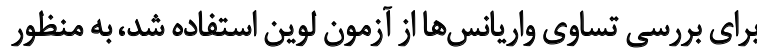

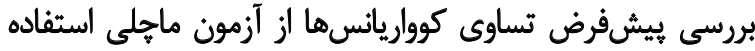

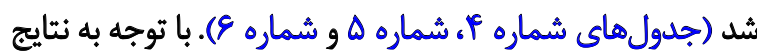

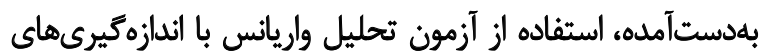

جدول f. آزمون كلوموكروف|سميرنف نمرات معناى زندكى، عملكرد خانوادكى و تابآورى

\begin{tabular}{|c|c|c|c|c|}
\hline سطح معنى دارى & درجه آزادى & آماره & توره & مؤلفه ها \\
\hline.$/ \mu \cdot$ & 10 & $\cdot M A$ & آزمايش & \multirow{2}{*}{ عملكرد خاثواده } \\
\hline.$/ \mu$. & 10 & ArA & كتترل & \\
\hline$\cdot / r \cdot$ & 10 & (1rg & أزمايش & \multirow{2}{*}{ معناى زندكى } \\
\hline$\cdot \pi$ & 10 & $\cdot M A$ & كتترل & \\
\hline$\cdot 1 \cdot \Lambda$ & 10 & $\cdot / r \cdot 1$ & آزمايش & \multirow{2}{*}{ تاب|أورى } \\
\hline . . vg & 10 & אז / & كتترل & \\
\hline
\end{tabular}

ثैं, 
جدول هـ. آزمون لوين در مورد همسانى واريانس نمرات معناى زندكى، عملكرد خانوادكى و تابآورى در مرحله بيش آزمون

\begin{tabular}{|c|c|c|c|c|}
\hline سطح معنى دارى & درجه آزادى دوم & درجه آزادى اول & تسبت F & مؤلفهـا \\
\hline$\cdot / r+F$ & ru & 1 & $V / 9 f$ & عملكرد خانواده \\
\hline | & rA & 1 & . AST & معناى زندكى \\
\hline.$/ F \Delta F$ & rA & 1 & . /AVS & تابآورى \\
\hline
\end{tabular}

انقّان

جدول و. نتايج آزمون ماجلى براى بررسى تناسب كوواريانسهاى متغيرهاى معناى زندكى، عملكرد خانوادىى و تابآورى

\begin{tabular}{|c|c|c|c|c|}
\hline Sig. & df & مجذور خى دو & ميزان ماهلى & اثر درونى \\
\hline.$/ . .1$ & $r$ & WN.D & . & معناىزندگى \\
\hline.$/ \Delta Q V$ & $r$ & $r / V \cdot r$ & . /AVT & عملكردخانوادگى \\
\hline.$/ . .1$ & $r$ & $r V / .9 V$ &.$/ \pi F$. & تابآورى \\
\hline
\end{tabular}

انقان

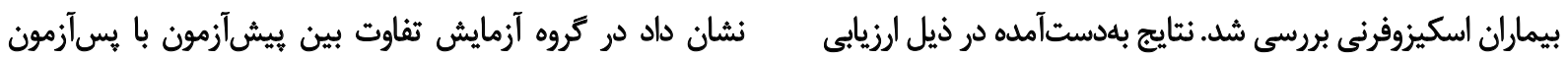

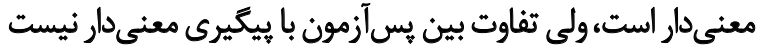

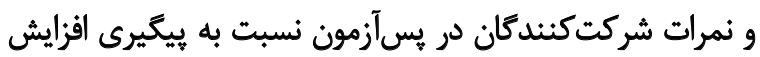

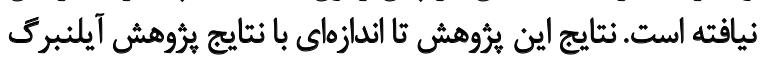

نتايج بهدست آمده در ارتباط با اثربخشى مداخله بر سطح نابآورى

جدول V. نتايج تحليل مانووا مربوط به ثأثير عضويت كروهها

\begin{tabular}{|c|c|c|c|c|c|}
\hline توان أمارى & مقدار اتا & سطح معنى دارى & $\mathbf{F}$ & ارزش & متغير \\
\hline . INA &.$\circ 9 x$ & ./ATV & . /AV9 & .1 .95 & تابأورى \\
\hline I Tat & . RTV & .1 .41 & r/an &.$/ T r V$ & عملكرد خانوادكى \\
\hline.$/ T r V$ & $\%$ H A &.$M r$. & $1 / 19$. & $\%$. A & معنا در زئدكى \\
\hline
\end{tabular}

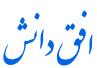

جدول A. مقايسه زوجى نمرات ثابآورى دو كروه در سهبار آزمون

\begin{tabular}{|c|c|c|c|c|}
\hline معنادارى & تفاوت ميانكين & آزمون & مرحله & متغيرها \\
\hline $.1 . .1$ & $-v / a g r$ & يس آزمون & \multirow{2}{*}{ ييشآزمون } & \multirow{3}{*}{ تاب|آورى } \\
\hline .10 .1 & $-V / \Delta Q V$ & ييكيرى & & \\
\hline.$/ 4 \cdot 8$ &.$\mu *$ & ييكيرى & هي آزمون & \\
\hline$\% 1 \%$ & $-1 / / r / \Lambda$ & يس آزمون & \multirow{2}{*}{ ييشآزمون } & \multirow{3}{*}{ عملكرد خانوادكى } \\
\hline .1 .18 & $-1 / \% 98$ & ييكيرى & & \\
\hline.$/ 9 \vee \Delta$ &.$/ .14$ & ييكيرى & يسآزمون & \\
\hline 1. & $-1 / M T$ & يس آزمون & \multirow{2}{*}{ ييش آزمون } & \multirow{3}{*}{ معنا در زندّى } \\
\hline. . 994 &.$- / N T$ & ييكيرى & & \\
\hline.$/ F 18$ & -1 & ييكيرى & يسآزمون & \\
\hline
\end{tabular}

انقان 
مثبت در زندگى در مراقبين اين بيماران داشته است و علت عدم

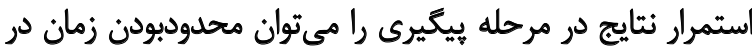

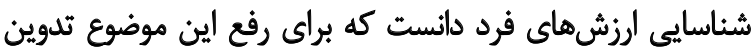
برنامه درمانى طولانىمدت إنت نياز است.

درنهايت متغير سوم يروهش به بروسى اثربخشى درمان مبتنى ئري

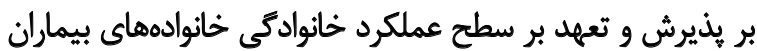

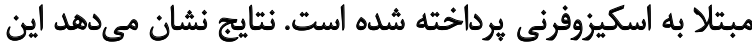

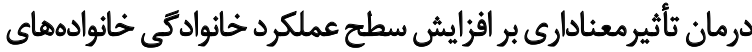

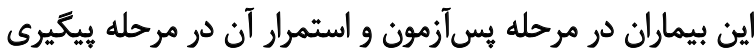

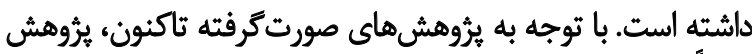

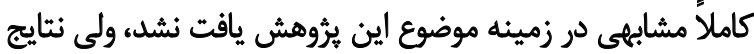

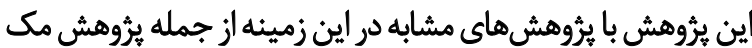

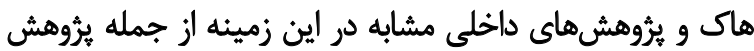

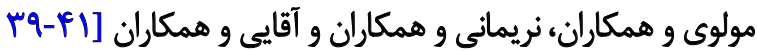

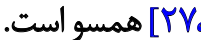

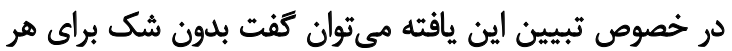

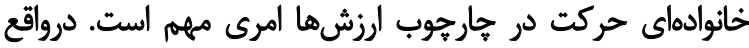

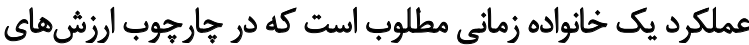

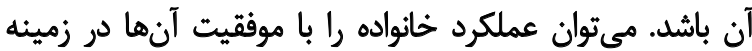

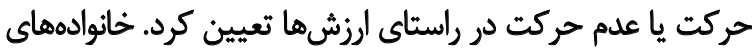

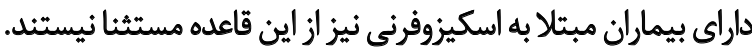

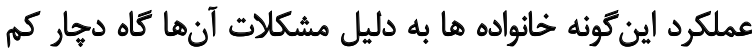

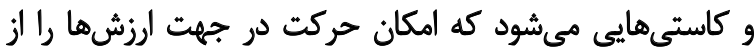

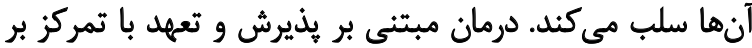

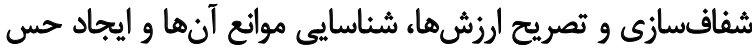

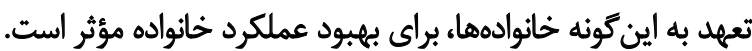

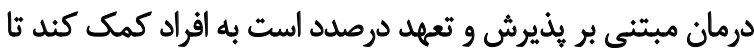

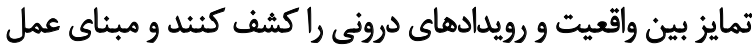

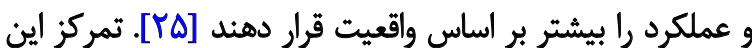

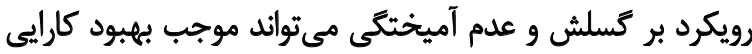

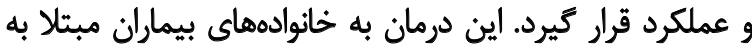

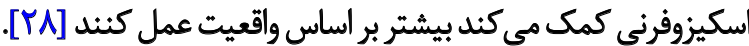

در سطح خانوادهها نيز همانند سطح فردى اين كسلش مئ تواند

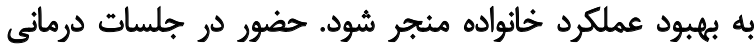

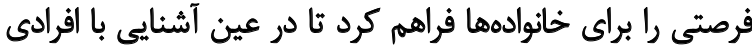

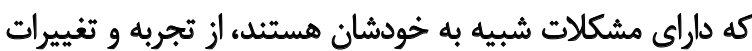

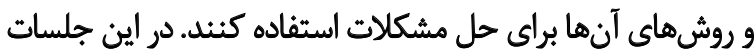

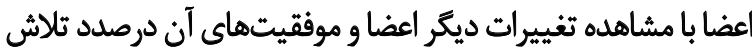

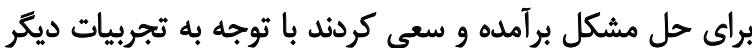

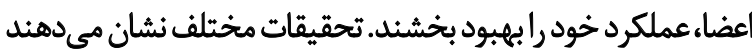

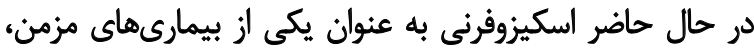

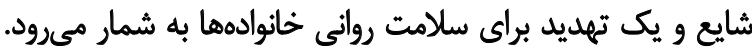

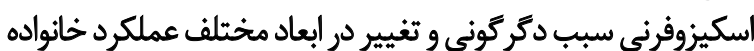

و همكاران همسو است [\&ץ]]. در خصوص تبيين اين يافته مى توان

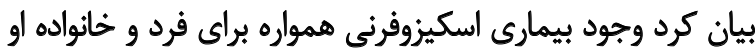

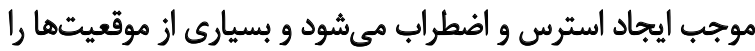

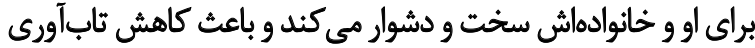

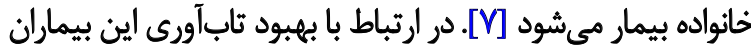

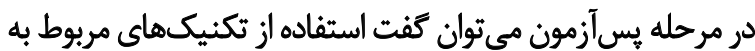

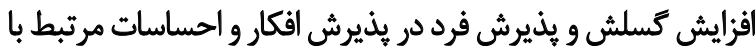

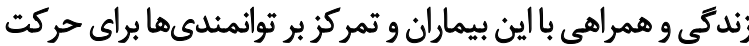

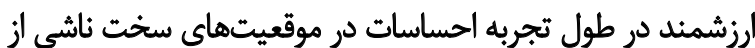

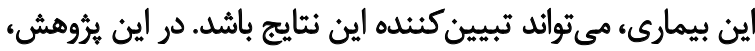

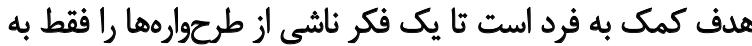

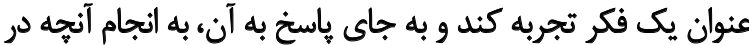

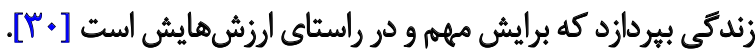

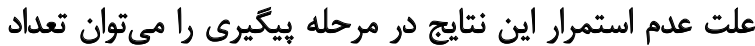

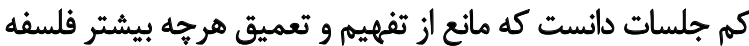

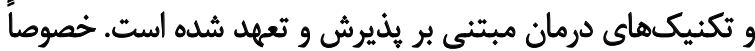

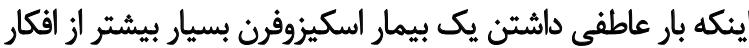

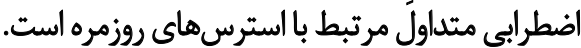

متغير دوم يثروهش اين بود كه درمان مبتنى بر بذيرش و تعهيد

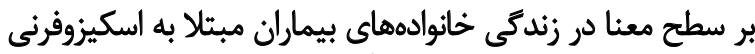

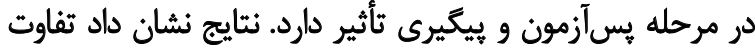

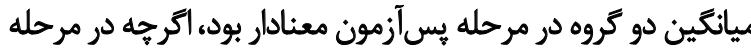

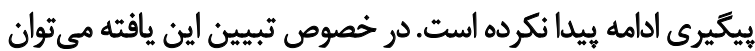

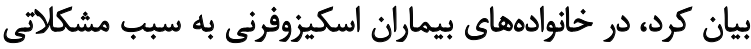

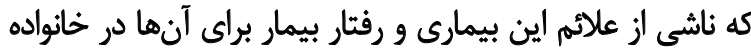

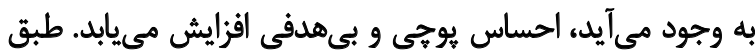

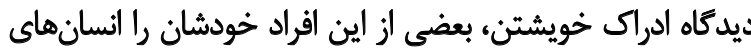

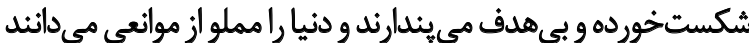

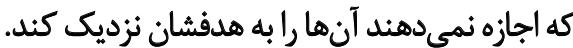

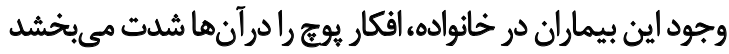

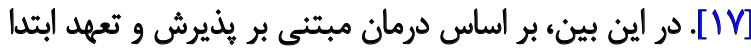

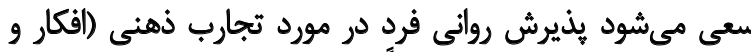

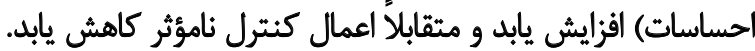

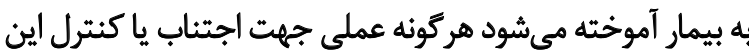

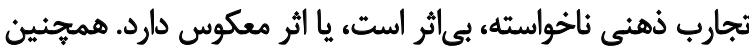

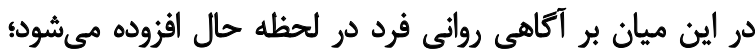

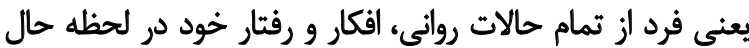

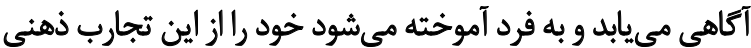

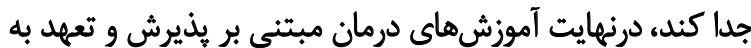

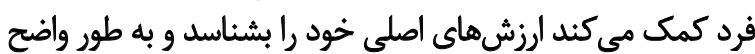

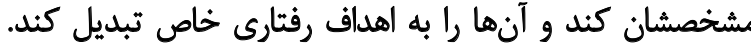

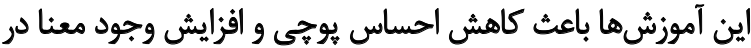

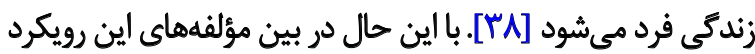

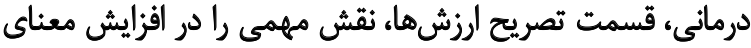




\section{مشاركت نويسندان}

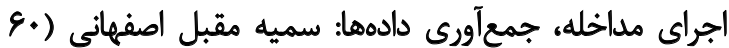

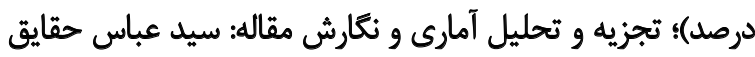

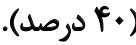

\section{ت تعارض منافع}

بنابر اظهار نويسئدكان اين مقاله تعارض منافع ندارد.
مىشود. وجود مشكلات روانى يكى از مههمثرين گروههاى هدف اين

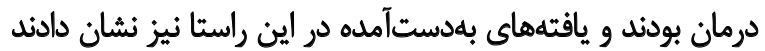

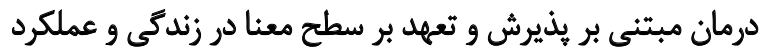
خانوادكى خانوادههاى بيمار ان مبتلا به اسكيزوفرنى مؤثر است

$$
\text { تشيجهيرى }
$$

نتايج اين يُروهش نشان ميدهد اين درمان، مى تواند به عنوان

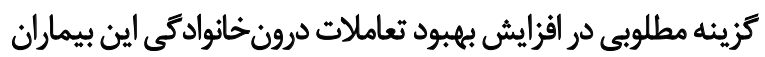

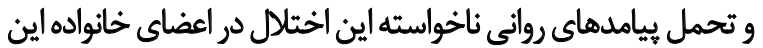

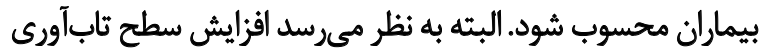

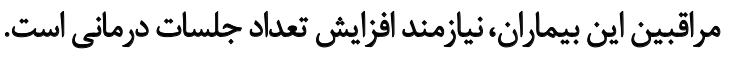

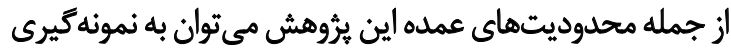

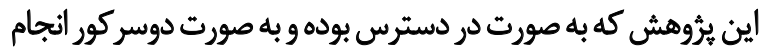

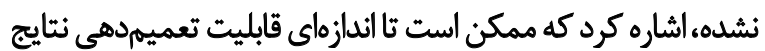

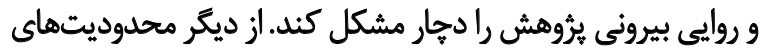

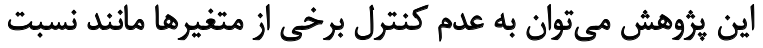

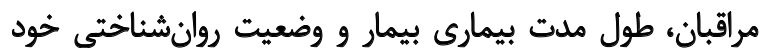
مراقبان اشاره كرد كه ممكن است در نتايج تأثيركذار بوده باشيد.

ويشنهاد مىشود به منظور افزايش تعميميذيرى يافتههاى

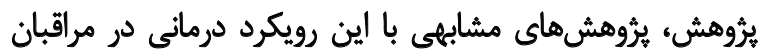

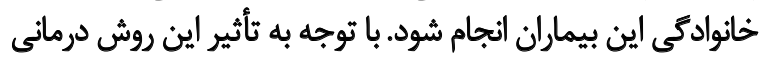

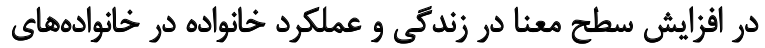

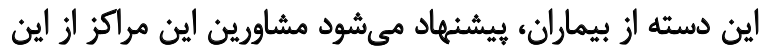

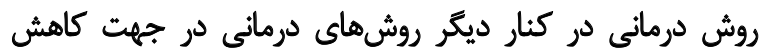

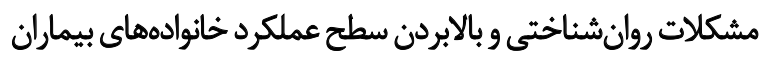

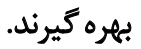

\section{ملاحظات اخلاقى}

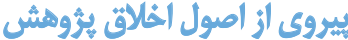

اين مقاله از كميته اخلاق دانشكاه آزاد نجفآباد داراى كد اخلاق

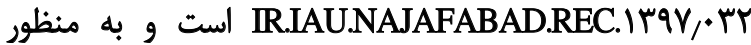

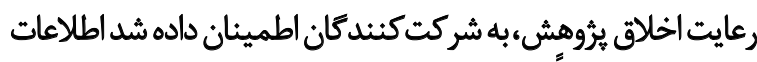

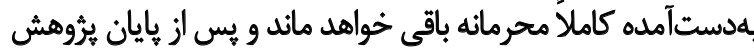

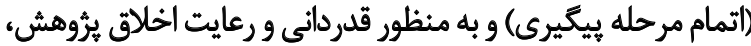

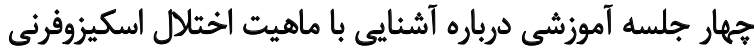

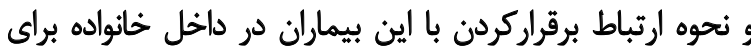

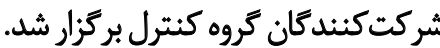

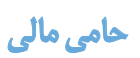

اين يزوهش حامى مالى نداشته است. 


\section{References}

[1] Sadati Z. [Comparison of metacognitive beliefs in schizophrenic patients, depressive disorder and normal group (Persian)]. Semnan Clinical Psychology Journals. 2008; 14(1):46-55.

[2] Roick C, Heider D, Toumi M, Angermeyer M. The impact of caregivers' characteristics, patients' conditions and regional differences on family burden in schizophrenia: A longitudinal analysis. Acta Psychiatrica Scandinavica. 2006; 114(5):363-74. [DOI:10.1111/j.16000447.2006.00797.x] [PMID]

[3] Kinsella KB, Anderson RA, Anderson WT. Coping skills, strengths, and needs as perceived by adult offspring and siblings of people with mental illness: A retrospective study. Psychiatric Rehabilitation Journal. 1996; 20(2):24-32. [DOI:10.1037/h0095388]

[4] Marsh DT. Families and mental illness: New directions in professional practice. New York: Praeger; 1992.

[5] Malekoti K. [Comparison of the implications of using mental health experts and family members of consumers of patient services in pursuing the treatment and rehabilitation of chronic mental patients and their need for care and treatment (Persian)]. Hakim. 2007; 6(2):1-30.

[6] Dyck DG, Short R, Vitaliano PP. Predictors of burden and infectious illness in schizophrenia caregivers. Psychosomatic Medicine. 1999; 61(4):411-9. [DOI:10.1097/00006842-199907000-00001] [PMID]

[7] Chen X, Mao Y, Kong L, Li G, Xin M, Lou F, et al. Resilience moderates the association between stigma and psychological distress among family caregivers of patients with schizophrenia. Personality and Individual Differences. 2016; 96:78-82. [DOI:10.1016/j.paid.2016.02.062]

[8] Ferro MA, Boyle MH. The impact of chronic physical illness, maternal depressive symptoms, family functioning, and self-esteem on symptoms of anxiety and depression in children. Journal of Abnormal Child Psychology. 2015; 43(1):177-87. [DOI:10.1007/s10802-014-9893-6] [PMID]

[9] Graziano S, Rossi A, Spano B, Petrocchi M, Biondi G, Ammaniti M. Comparison of psychological functioning in children and their mothers living through a life-threatening and non life-threatening chronic disease: A pilot study. Journal of Child Health Care. 2016; 20(2):174-84. [DOI:10.1177/1367493514563854] [PMID]

[10] Connor KM, Davidson JR. Development of a new resilience scale: The Connor-Davidson Resilience Scale (CD-RISC). Depression and Anxiety. 2003; 18(2):76-82. [DOI:10.1002/da.10113] [PMID]

[11] Yates TM, Masten AS. Fostering the future: Resilience theory and the practice of positive psychology. In: Linley PA, Joseph S, editors. Positive Psychology in Practice. Hoboken: John Wiley \& Sons Inc; 2004.

[12] Mesrabadi J, Jafariyan S, Ostovar N. [Discriminative and construct validity of meaning in life questionnaire for Iranian students (Persian)]. International Journal of Behavioral Sciences. 2013; 7(1):83-90.

[13] Asghari Nekah SM, Jansouz F, Kamali F, Taherinia S. [The resiliency status and emotional distress in mothers of childrenwith cancer (Persian)]. Journal of Clinical Psychology. 2015; 7(1):15-27.

[14] Luthar SS, Cicchetti D, Becker B. The construct of resilience: A critical evaluation and guidelines for future work. Child Development. 2000; 71(3):543-62. [DOI:10.1111/1467-8624.00164] [PMID] [PMCID]

[15] Steger MF, Oishi S, Kashdan TB. Meaning in life across the life span: Levels and correlates of meaning in life from emerging adulthood to older adulthood. The Journal of Positive Psychology. 2009; 4(1):43-52. [DOI:10.1080/17439760802303127]

[16] Frankl V. Man's search for meaning. New York: Simon \& Shuster; 1984.
[17] Marco JH, Guillén V, Botella C. The buffer role of meaning in life in hopelessness in women with borderline personality disorders. Psychiatry Research. 2017; 247:120-4. [DOI:10.1016/j.psychres.2016.11.011] [PMID]

[18] Sarmiento IA, Cardemil EV. Family functioning and depression in lowincome latino couples. Journal of Marital and Family Therapy. 2009; 35(4):432-45. [DOI:10.1111/j.1752-0606.2009.00139.x] [PMID]

[19] Tantirangsee N, Assanangkornchai S, Marsden J. Effects of a brief intervention for substance use on tobacco smoking and family relationship functioning in schizophrenia and related psychoses: A randomised controlled trial. Journal of Substance Abuse Treatment. 2015; 51:30-7. [DOI:10.1016/j.jsat.2014.10.011] [PMID]

[20] Solomon P. Interventions for families of individuals with schizophrenia. Disease Management and Health Outcomes. 2000; 8(4):211-21. [DOI:10.2165/00115677-200008040-00004]

[21] Nassiri S, Ghorbani M, Adibi P. [The effectiveness of acceptance and commitment-based treatment in quality of life in patients with functional gastrointestinal syndrome (Persian)]. Journal of Clinical Psychology. 2016; 4(27):102-93.

[22] Hayes SC, Luoma JB, Bond FW, Masuda A, Lillis J. Acceptance and commitment therapy: Model, processes and outcomes. Behaviour Research and Therapy. 2006; 44(1):1-25. [DOI:10.1016/j.brat.2005.06.006] [PMID]

[23] Wicksell RK, Kanstrup M, Kemani MK, Holmström L, Olsson GL. Acceptance and commitment therapy for children and adolescents with physical health concerns. Current Opinion in Psychology. 2015; 2:1-5. [DOI:10.1016/j.copsyc.2014.12.029]

[24] Baradaran M, Alipour HZ, Farzad V. [Comparison of effectiveness of acceptance and commitment therapy and motivational interviewing on decreasing anxiety, depression, stress and increasing hope in essentia hypertensive patients (Persian)]. Clinical Psychology. 2016; 8(4):95-105.

[25] Jansen JE, Morris EM. Acceptance and commitment therapy for posttraumatic stress disorder in early psychosis: A case series. Cognitive and Behavioral Practice. 2017; 24(2):187-99. [DOI:10.1016/j.cbpra.2016.04.003

[26] Eilenberg T, Fink P, Jensen J, Rief W, Frostholm L. Acceptance and Commitment Group Therapy (ACT-G) for health anxiety: A randomized controlled trial. Psychological Medicine. 2016; 46(1):103-15. [DOI:10.1017/ S0033291715001579] [PMID]

[27] McHugh L. A new approach in psychotherapy: ACT (Acceptance and Commitment Therapy). The World Journal of Biological Psychiatry. 2011; 12(Suppl. 1):76-9. [DOI:10.3109/15622975.2011.603225] [PMID]

[28] Peterson LG, Pbert L. Effectiveness of a meditation-based stress reduction program in the treatment of anxiety disorders. The American Journal of Psychiatry. 1992; 149(7):936-43. [DOI:10.1176/ajp.149.7.936] [PMID]

[29] Saeedmanesh M, Azizi M. [The effectiveness of acceptance commitment therapy on acceptance and defense style of parent with autistic children (Persian)]. Therapy on the parent with denial defense mechanism. Middle Eastern Journal of Disability Studies. 2016; (7):1-8.

[30] Mohamad SM. [The effectiveness of group-based acceptance and group commitment on the satisfaction of mothers of children with cancer (Persian)]. Semnan Clinical Psychology. 2017; 34(2):29-35.

[31] Moghtadayl M., Khosh Akhlagh H. [Effectiveness of acceptance- and commitment-based therapy on psychological flexibility of veterans' spouses (Persian)]. Tebe-E-Janbaz. 2015; 7(4):183-8. 
[32] Delavar A. [Research methods of psychology and education (Persian)]. Tehran: Virayesh; 2017.

[33] Momeni KH, Alikhani M. [The relationship between family functioning, differentiation of self and resiliency with stress, anxiety and depression in the married women Kermanshah City (Persian)]. Journal of Family Counseling and Psychotherapy. 2013; 3(2):297-329.

[34] Samani S, Jokar B, Sahragard N. [Effects of resilience on mental health and life satisfaction (Persian)]. Iranian Journal of Psychiatry \& Clinical Psychology. 2007; 13(3):290-5.

[35] Epstein NB, Baldwin LM, Bishop DS. The McMaster family assessment device. Journal of Marital and Family Therapy. 1983; 9(2):171-80. [DOI:10.1111/j.1752-0606.1983.tb01497.x]

[36] Ghamari M. [The comparison of family functioning dimensions and quality of life and their relationships among addicted and non-addicted persons (Persian)]. Journal of Research on Addiction. 2010; 5(18):55-68.

[37] Steger MF, Frazier P, Oishi S, Kaler M. The meaning in life questionnaire: Assessing the presence of and search for meaning in life. Journal of Counseling Psychology. 2006; 53(1):80-93. [DOI:10.1037/0022 0167.53.1.80]

[38] Forman EM, Herbert JD. New directions in cognitive behavior therapy: Acceptance-based therapies. In: O'Donohue WT, Fisher JE, editors. General Principles and Empirically Supported Techniques of Cognitive Behavior Therapy. Hoboken: John Wiley \& Sons; 2009.

[39] Molavi P, Mikaeili N, Rahimi N, Mehri S. [The effectiveness of acceptance and commitment therapy based on reducing anxiety and depression in students with social phobia (Persian)]. Journal of Ardabil University of Medical Sciences. 2014; 14(4):412-23.

[40] Narimani M, Alamdari E, Abolghasemi A. [The study of the efficiency of acceptance and commitment-based therapy on the quality of infertile women's life (Persian)]. Journal of Family Counseling and Psychotherapy. 2014; 4(3):387-405.

[41] Aghaei A. [The effectiveness of acceptance and commitment therapy on vitality and resiliency in patients with psoriasis (Persian)] [MA. thesis]. Khorasgan: Islamic Azad University; 2013. 